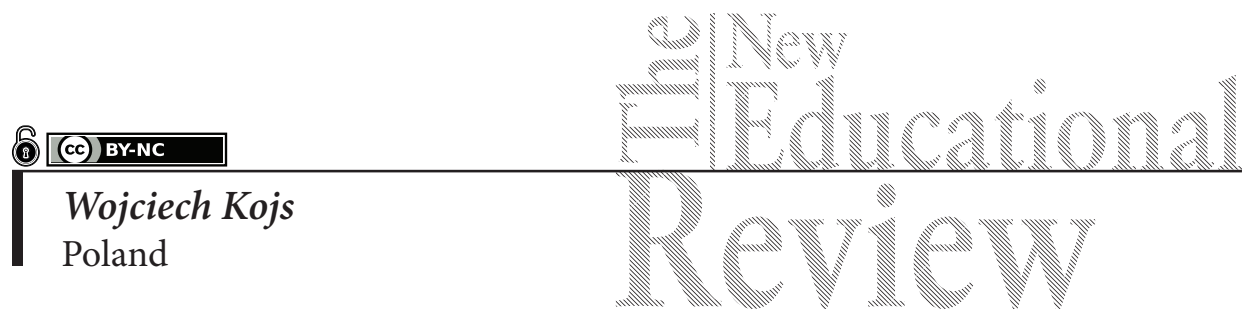

\title{
The Educational Value of Control and Evaluation Activities
}

DOI: 10.15804/tner.2019.57.3.08

\begin{abstract}
Education is a metaprocess focused on causing changes in individual and social resources of experience, knowledge, skills, attitudes, beliefs and aspirations, as well as in the state of health and physical fitness. This system of processes consists of many diverse interrelated interactions, actions, acts, deeds and activities, with many related elements and components, and among them control and evaluation activities. The purpose of the article is to present the results of analyzes and thoughts related to the determination of the role of these activities among other educational acts, related in particular to cooperation and mutual interaction. It goes well beyond the commonly accepted so-called school and colloquial understanding of these terms. They are treated primarily as cognitive and research activities, as well as valuing activities, as subject-making, person-forming and sociogenic tools. The basis of the research was a diachronic-synchronous model of the full, broadly understood act of educational activity. The resulting conclusions indicate their fundamental role in education.
\end{abstract}

Keywords: education, value, structure of activity, subject of activity, control, evaluation, comparative analysis, praxis pedagogy

\section{Introduction}

The concepts of control and evaluation are usually treated as the final stages of an action or activity. They are associated with institutions in which behavior is shaped and regulated by means of punishment and rewards. Such institutions 
include the school in which the basic tool of regulation and course of work is the system of classification and evaluation of a student and teacher's work achievements. For this reason, they are the subject of numerous research and studies, including in education sciences. Most often, however, they concern teachers' control and evaluation activities, and to a lesser extent students. They also primarily concern the control and assessment of achieved teaching and learning outcomes, and not the educational process of their creation and course. Failures related to the functioning of the grading and performance evaluation system are not expressed and are not limited only to low grades. Very often, they cause serious consequences in the area of physical and mental health, in a low level of trust, an excess of consumer attitudes and a shortage of creative attitudes (Sztompka, 2003). The source of failures emerges from the nineteenth-century work pattern of a teacher and a student, is still persisting in completely changed social and cultural communication systems and civilizational consequences that have been resulting from them. The educational system derived from research, including experimental work on education, requires a radical change on the optimal use of the creative potential of participants in education processes, especially teacher and student.

The main purpose of the study is to define the role of control-evaluation activities in: (1) creating systems of unitary and social education, (2) noticing and shaping full, conscious acts of education (educational acts) and (3) determining knowledge-creative, self-creative and sociogenic functions (4) generating educational: opportunities and threats, successes and failures.

The direction and the way of constructing answers to questions resulting from the above-mentioned goals are determined by the assumption that every human being - in its essence - is a biologically, socially and culturally defined system of educational communication. The system defined by (1) the processes of producing and sending verbal and non-verbal messages, (2) the processes of receiving (understanding) and creating a feedback message - the response and its transmission. The processes of creating, transmitting and receiving messages are associated with emotional and volitional processes. The basic role in such perceived education is fulfilled by the general cognitive-praxis structures produced in it, general knowledge of the reality and the values that give them sense.

Control and evaluation activities, which essentially are researchable and valuative ones, are the necessary components of every form of conscious and subconscious human activity. It means that any complex system: a person, social group or institution, through integrated and operationalized control and evaluation processes, educationally regulate and shape their own behavior in communication activities. This applies both to the internal environment of a particular system and 
to the external social environment with which the system remains in causal relationships. In this situation, school systems are a particular case of such perceived universal education.

School systems, with some changes made, can contribute to thoughtful shaping of the ability to select and integrate strong information interactions generated by various external environment systems. These abilities are closely related to the inherent properties of control and evaluation activities - co-creation with subjects of activities not only of knowledge and skills but also of operational, general meta-knowledge systems and cognitive and valuing meta-skills.

From the above-mentioned structure of the main action, i.e. the act, the main thesis of the study arises - the basic unit of educational activity is the educational whole, which creates optimal conditions for shaping the full system of educational values, including universal values. Educational values are the both listed component activities and their individual elements as well as the causal relationships that connect them. Their lack may create highly adverse educational situations. However, it can create desirable problem situations, which, introduced intentionally, should trigger an educational process of creative effort allowing the person to familiarize themselves with the problem, its understanding and transformation into a form that internally integrates participants in this process.

\section{Methodological and theoretical aspects of the study}

The discussed control and evaluation activities contribute to the so-called main activities (acts and complex forms of activity), as well as their constituent activities: preparatory, implementation, application, control-evaluation and correction activities. The component activities determine the diachronic nature of the main activity - ordering in time and co-occurrence. The preparatory activities precede implementation activities, and these ones - application activities. Each of these activities is closely related to the other three - control, evaluation and corrective. The synchronous aspect refers to the co-occurrence in each conscious action of the following elements: the subject, purpose, object of change, means, methods and conditions as well as partial and final effects. They determine the transformation and production of the content of activities, and are visible - among others in every dialogue - a complex communication activity.

The issues presented above clearly indicate that when they are developed and theoretical and methodological foundations are presented, the need to reach to the theory of praxeological sciences, showing a comprehensive and general approach to 
the features of all forms of conscious human activity arises. Praxeology is a general theory, and at the same time a methodology of cognitive and research activities, it is a methodological and axiological chance of education for each conscious and creatively acting person and group. It does not only mean a "purely" theoretical aspect, but also experiencing the process of creating and developing his/her own, and yet constantly tested theories of actions. In the past, this way was pointed out by Tadeusz Kotarbiński (1965) - the creator of praxeology - who stated that the principles of efficient action appear as a result of sometimes arduous observations and experiences, as well as recognition of the knowledge-making role of successful and unsuccessful ventures. Kotarbiński also identified the needs and directions for further development of praxeology. W. Gasparski (1983) included these directions in his works, building a theory of preparatory actions important for pedagogy and education. It should also be noted here that J. Gnitecki (1996) created in this respect the methodology of pedagogical praxeology.

An important role in this article is played by the works of D. Benner (1973, 1990, 1986, 1987), who in the context of analysis of German (cf. Derbolav 1975, 1976) and Finnish literature (Uljens 1994, 2010; Hintikka 1982) presented his own praxeological concept of general pedagogy. He pointed to its Greek roots (practical philosophy) and its revival in the age of enlightenment, among others, in the works of J.J. Rousseau, I. Kant, A. Humboldt, F. Schleiermacher and J. Herbart. The idea they expressed concerned a non-hierarchical and non-teleological attitude to pedagogical practice, which is associated with the emergence of modern pedagogy. Hence, we are talking about global praxeology (theory of human action) and universals of the problem of action.

The analysis and interpretation, as well as the methods of reaching significant statements, are embedded in a diachronic-synchronous, descriptive model of the full structure and function of conscious action (conscious act). Such a model, pointing to the necessary elements and relations between elements of action (action), may constitute an eligible tool for studying structural and functional components of educational reality and adjudicating on the consequences of the equilibrium states or deficiency states and excesses occurring in them.

An important methodological attention referring to the above issues concerns the basic cognitive (mental) operations, which determine the values used in research of methods, including observations and generalizations and the theories created: descriptions, explanations, projects, diagnoses, forecasts, and also comparative analyses of their basics. Comparative activities should be considered fundamental cognitive-research processes, which are present and available to everyone "waiting for their creative application". In control and evaluation activities, they are 
a necessity, because they co-create and define their cognitive-research, axiological and utilitarian value.

\section{Diachronic and synchronic analysis of educational and control-evaluation activities}

Basing on the analysis of literature that treats the structures and functions of activities, activities, deeds, the elements repeated in them and the phases repeated in their course (periods, links) were distinguished. Such behavior takes into account the diachronic and synchronic nature of the discussed forms of activity, which enables the construction of a deed model as a structural whole - an important tool in research on human functioning and development.

The synchronic approach to educational activities is formed by: (1) the subject of activity (action), meta-informational, mind structure which manages it; (2) the goal of an activity; (3) an intellectual and/or material object; (4) means of action; (5) methods of activity as an organization of means, enabling the transformation of an object and the realization of a goal; (6) conditions of an activity; (7) results of activity; (8) the environmental context of action (act). The adopted, simple way of understanding named elements is as follows: operation on the meta-informative structure of the mind that manages the action. The purpose of the action is an image of the desired, future state of its mental or/and material resources arising from the needs of the individual. The subject of the activity is mental or/and material resources changed in the course of achieving the goal; action measures on intellectual resources or support materials by which the subject of the action is to be changed. Operating conditions are the space-time and biopsychic factors determining the application and use of means and methods. The results of the action are anticipated and unforeseen, positive and negative, partial and final effects. In addition, the effects are the effects of carrying out partial tasks in the course of an action and taking application measures based on the final results. The environmental context of the action are social, natural, economic and cultural factors affecting the course of the act (see below Parallel 1).

The diachronic dimension of the problem under consideration is determined by successively occurring and co-existing, interdependent activities: (1) preparatory (application); (2) implementation; (3) application; (4) control; (5) evaluation; (6) corrective. Such activities may consist of specific actions assigned to them and create networks of activities. Learned, studied and experienced activities along with the above-mentioned elements, lead to the formation of subjective and inter- 
subjective theories of actions, and after meeting the appropriate methodological rigori, to shaping scientific theories of actions, deeds. The discussed problems of diachrony and synchrony are the problems of organization and management of individual and group activities, including educational activities; they are the problems of organization and management of knowledge and skills (see below Parallel 2).

Taking into account the above-distinguished elements, co-creating every conscious action (subject, goal, etc.) and the constituent actions of the main action, by appropriate signment, we can relate each element to each constituent action and thus receive 48 different knowledge content and functions and include them in the parallel also taking into account the content of the main activity (see Table 1).

Table 1. A network of activities consisting of a main activity and component activities enabling the analysis of 48 differing content and functions of knowledge units

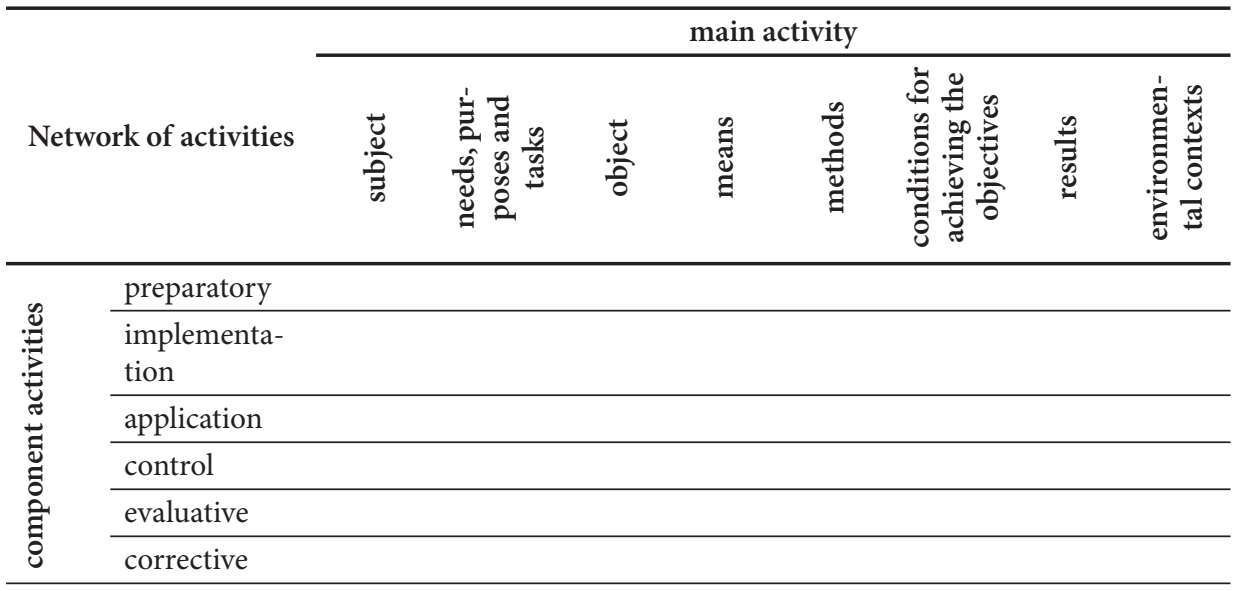

Source: Own study

Parallel 1 - content of main activity elements and content of constituent activities:

1) the subject of the main activity and six subjects of the component activities: preparatory, implementation, application, control, evaluation and corrective;

2) needs, objectives and tasks of the main action and six groups of purposes and tasks of the constituent activities (listed above);

3) the subject of the main activity and six subjects of the component activities (listed above);

4) main action and constituent action means (listed above); 
5) main activity methods and six groups of constituent activity methods (listed above);

6) conditions for achieving the objectives of the main activity and conditions for achieving the objectives of the constituent activities (listed above);

7) results of the main activities and the results of the six component activities (listed above);

8) environmental contexts of the main activity and six constituent activities (listed above).

In the above way, we obtain material for analyzing the function of the main activity and the role of elements in creating knowledge about particular component activities as a whole arising from the diversified content of their elements. We also receive material indicating the possibilities of creating: monographic knowledge about individual elements of activities, obtained through the use of comparative analysis, and also knowledge about subjects, goals, objects, means, methods, conditions, results and their environmental determinants. It is important to note that material presented in this way includes the analysis of elements of control and evaluation activities and the possibility of determining their specific nature. When asked about the nature and specific features of knowledge about the component activities undertaken in the context of the main activity, the answer will be the parallel of component activities with elements forming individual activities.

Parallel 2 - the main action and their elements:

1) Knowledge about preparatory activities: possessed mental and material resources; subjects of activities, their needs, and goals, objects of educational change; means and methods of transforming the object of change; the conditions of preparatory activities; the results of preparatory actions; about environmental contexts of preparatory activities;

2) Knowledge about implementation activities: characteristics of their subjects and possessed mental and material resources; goals and tasks; objects of change; means and methods; conditions of achieving goals; partial and final results; environmental conditions of implementation activities;

3) Knowledge about application activities; applications of partial results which were researched during the operation and application of the final results obtained; features of their subjects; needs and goals; application of the results obtained; about the object of changes caused by the application action; means and methods of causing changes in the object of application activities; about the conditions of applying the application activity; about the results of applying the application activity; environmental contexts of applying the application activity; 
4) Knowledge of control and evaluation activities: characteristics of their entities and possessed mental and material resources; the needs, goals and tasks of taking them up; research and evaluation items for control and evaluation activities; of means, methods and conditions for achieving their goals and tasks; of the results of research, control and evaluation activities; of the environmental contexts of their taking up and running;

5) Knowledge of corrective actions applies to all component activities of the main activity related to unforeseen defects, mistakes made as a part of the accomplishment of objectives and component activities: of entities of actions and possessed mental and intellectual resources; assumptions, goals and tasks of corrective actions; of the objects of these activities; means, methods, and conditions for their implementation; effects of corrective actions; of environmental conditions.

Knowledge of particular elements of activities, acquired taking into account their place and close relationships with each component action, creates specific and basic knowledge of education and the theory of education, its value, and importance in its entirety, which is a full act of educational activity. Similarly, we can talk about creating the knowledge of individual component activities, their specificity and values, and the necessary relationships. Together with the knowledge of their elements and equally necessary connections, we get an outline of knowledge of the structures and functions of the synchronic-diachronic, dynamic education model.

The analysis of diachronic features of the main activity and component activities shows that control and evaluation activities relate to all these activities and changes that occur in them, including the elements forming them. Thus, it can be said that they co-create and co-decide on the quality of preparatory, implementation and application activities of the main activity, as well as on the scope and quality of their own activities and meta-activities and - also accompanying all activities, that are important because of learning from errors - corrective actions.

In the description of educational activities, it is important to note the participation of consciousness, subconsciousness and unconsciousness in these activities. It is important here not only to master specific knowledge and skills, attitudes and competences, but also to shape subconscious, dominant structures that determine rapid decisions. Therefore, what conditions should meet the process of education, especially control and evaluation processes, so that the deep layers of the subconscious are possible of high quality resources of the mind and human life. This question is to be left unanswered, as it demonstrates the educational problem of functioning control and evaluation systems in complex structures of highly developed societies. 


\section{Discussion}

The special role of control and evaluation activities in the full act of educational act about the functioning of man in the world, that is, about the "gateway" to reality and the "gateway" to subjects of life

The use of categories of control and assessment requires the use of such general knowledge that would embrace and control the content of events that are the subject of control and evaluation. To take into account the importance of such requirements, the category of activity should be used. This means that when using the concepts of control and evaluation, we take into account the general diachronic and synchronic nature of their structures. We note that it is the subject of the activity that should have such features that allow it to manage the activity, including the course of testing and evaluation of the subject of control and evaluation. The synchronous aspects of such activities are presented as the first summary presents. It indicates the components, guided by the objectives of these activities. When we pose a question about their functions, in response we get the statement that each element and all together serve the subject in monitoring the control and assessment of the entirety of activities and their individual parts. They form a network of relationships along with information and metainformation structures, and by supporting themselves they create and develop knowledge and meta-knowledge of control and evaluation.

Control and evaluation activities create cognitive-research and emotional values. They join values that are the basis for taking them up, and which guide the activity in relation to the objects of these activities. Comparative analyses are their basis, so the value of control and evaluation is co-determined by the value of the comparative analysis. When we simplify these activities, focusing and satisfying quickly obtained results, confident in our competence, convinced of the simplicity of the task undertaken, we can make mistakes that result in multiple consequences of a cognitive nature (e.g. untruth, false judgments, and anti-knowledge), ethical, health or economic. The control and evaluation activities become the tools of the subject for searching, discovering, releasing, experiencing, and shaping such values as the sense of freedom, dignity, trust, truth, solidarity, and wisdom.

The question that is learned, formulated and asked by someone and the answer learned ready for the question, generally remain a foreign element in the mental resources. The same question, acquired with the activities leading to its formulation, considered by us as important, leads to the personalization of this process 
and the emergence of a shared cognitive and social value. The same applies to the answer.

In the diachronic and synchronic analysis of the structures and functions of conscious actions, main activities and components, in determining the causal relations between them, the analysis of management actions, that is entities' activities, is of crucial importance. The structures and functions of entities are being born in the processes of recognizing and assessing needs, and their generators are control and researching, and evaluating and researching activities. These activities are necessary for the formation and development of entities and the empowerment of action structures. As a consequence, it can be said that control-evaluation activities are the gates to the structures and functions of the subject and subjectivity.

Control and evaluation activities as research activities are addressed not only to the subject but also to the outside world. When we look at the component activities listed above and stop at the "control-evaluation activities" item, we notice that they refer to all component activities and their elements, and through them, to the reality they concern. They, therefore, can be called "gates to external reality." This issue arises when the fundamental cognitive value of comparative activities is analyzed. The special value of a control and evaluation activity as a research and evaluating activity results from the fact that it refers to the whole processes of education and determines them, or, more broadly, life. It defines their parts and relationships between them; it is an activity that pervades other activities, enabling the perception of significant dependencies, and the creation of their theories and meta-theories, the creation of multi-level images of controlled and assessed reality. Control and evaluation activities, with their entities, also cover themselves in processes of diachronic and synchronic self-knowledge or internal control and evaluation in the case of an organization (institution).

In social communication, which was mentioned in the Introduction, and in the dialogue that is its manifestation, the intellectual resources possessed by the interlocutors that determine its value play an important role. They can be assigned to the functions such as activity management, mediation in action, participation in evaluation and interpretation. The categorizing of reality plays a fundamental role by means of cognitive categories, related to comparative, control and evaluation activities. We categorize all objects and events that we encounter in the surrounding environment, and this activity is necessary for action and indispensable for survival. The conceptual categories that we create are the basis of language and thinking. Our ability to construct meanings depends, largely, on the system of cognitive categories that we adopt and is one of the most important skills that enable us to survive (Kövecses 2011,pp. 37, 64). 
Considering the above distinguished spatiotemporal aspects of conscious actions, in the course of their fulfillment not only objects of actions and the level of achieved results are subjects to change, but - taking into account the awareness aspect - all its elements. Paying attention mainly to the goals and pursuit of the effects of action is a great simplification and waste of educational potentials, contained in the full structures and functions of action. Thus, it seems that the presented model of a full act of educational activity can be considered a useful contribution to the ongoing discussion on education reform.

\section{Conclusion}

In relation to the objectives of the article outlined above, it will be justified to state that each conscious action is co-created by control and evaluation activities. As it was demonstrated in the article, these activities participate in the creation and functioning of individual and social education systems, in perceiving and shaping full, conscious education acts (educational acts), in determining knowledge-making, person-forming and sociogenic functions in the transformation of education systems, as well as in educational generating: opportunities, threats, successes and failures. The analysis of the conscious action model shows that control and evaluation activities are multifunctional generators of knowledge and skills, as well as the source and implementation of values.

\section{References}

Benner, D. (1973). Hauptströmmungen der Erziehungswissenschaft. München: List Verlag. Benner, D. (1986). Die Pädagogik Herbarts. Weinheim und München: Juventa Verlag. Benner, D. (1987). Allgemeine Pädagogik. Weinheim und München: Juventa Verlag. Benner, D. (1990). Wilhelm von Humboldts Bildungstheorie: Eine problemgeschichtliche Studie zum Begründungszusammenhang neuzeitlicher Bildungsreform. Beltz: Juventa Verlag.

Derbolav, J. (1975). Umrisse einer Praxeologie. In: Pädagogik und Politik: eine systematisch-kritische Analyse ihrer Beziehungen mit einem Anhang zur Praxeologie. Stuttgart: Kohlhammer.

Derbolav, J. (Hrsg.) (1976). Kritik und Metakritik der Praxeologie, insbesondere der politischen Strukturtheorie. Henn: Northwestern University.

Gasparski, W. (1983). The Art of Practical Problem Solving as a Subject of Scientific Exploration. An Appeal for Modern Praxiology. In: Perspectives on Adaptation, Environment and Population. New York: Praeger. 
Gnitecki, J. (1996). Metodologiczne problemy pedagogiki prakseologicznej [Methodological problems of praxeological pedagogy]. Zielona Góra: Wyd. WSP. Hintikka, J. (1982). A dialogical model of teaching. Synthese 51:39-60.

Kotarbiński, T., (1965). Traktat o dobrej robocie [The treaty on good work]. Wrocław Warszawa-Kraków: Wydawnictwo PAN.

Kövacses, Z. (2006). Language, Mind, and Culture: A Practical Introduction. Oxford: Oxford University Press.

Sztompka, P. (2003). Trust: a Cultural Resource. In: The Moral Fabric in Contemporary Society. Leiden and Boston: Brill.

Uljens, M. (1994). A study on the foundations of cognitivism. Vasa: Via Mathesis Press. 